\title{
EL CRISTO CRUCIFICADO DE VELÁZQUEZ: TRASFONDO HISTÓRICO-RELIGIOSO
}

\author{
POR \\ ALFONSO RODRÍGUEZ G. DE CEBALLOS
}

\begin{abstract}
En este escrito se establece la hipótesis, fundada en hechos históricos comprobados, de que el cuadro de Velázquez, Cristo crucificado, fue mandado pintar entre el verano y el otoño de 1632 por Jerónimo de Villanueva, una vez interrumpido el proceso inquisitorial en que se había visto envuelto. Pero no como penitencia impuesta por el Santo Oficio, sino como un acto expiatorio entre los muchos que se organizaron en Madrid con motivo de la cruel profanación de un Crucifijo por judíos portugueses que, en julio de aquel mismo año, fueron condenados a muerte en público Auto de Fe.

Palabras clave: Cristo Crucificado. Velázquez. Jerónimo de Villanueva. Convento de San Plácido. Herejía alumbradista.

The author establishes the hypothesis, based on verifiable historical events, that Velazquez's Christ on the Cross was commissioned between the summer and autumn of 1632 by Jerónimo de Villanueva, when the inquisitorial proceedings in which he had been implicated were discontinued. This commision was not, however, imposed as penitence by the Holy Office; it was one among many expiatory acts organized in Madrid occasioned by the desecration of a Crucifix by Portuguese Jews, condemned to die in a public Auto-da-fe in July of that year.
\end{abstract}

Key words: Christ on the Cross. Velázquez. Jerónimo de Villanueva. Convent of San Plácido. Illuminated Heresy.

Se ha subrayado por casi todos los estudiosos el hondo calado religioso de este Cristo Crucificado en el que Velázquez, aun sin renunciar a sutilezas técnicas y excelencias de estilo, sintió profundamente el asunto, no mostrándose tan cerebralmente frío y distante como en otras pinturas de carácter sagrado. Esto pienso que requiere una explicación, que resulta plausible cuando se indaga en el trasfondo histórico del cuadro. Para entenderlo es preciso adelantar algunos prolegómenos.

La tendencia actual de la crítica es anticipar la fecha del lienzo a los primeros años de la década de 1630 , concretamente en torno a 1632, tanto por razones estilísticas como técnicas. Palomino había situado aparentemente su factura en 1638, después del retrato del duque de Módena, quien visitó Madrid en ese año. Pero la expresión «hizo también Velázquez por este tiempo un célebre cuadro de Cristo Crucificado difunto» no hay que interpretarla a la letra, pues con «este tiempo» aludió seguramente al transcurrido inmediatamente después de la vuelta del pintor a Madrid tras el primer viaje a Italia ${ }^{1}$. Así lo interpretó don Manuel Gómez More-

' El Parnaso español pintoresco y laureado, Madrid 1724; edición moderna de M. Aguilar, Madrid 1947, p. 904.

$A E A$, LXXVII, 2004, 305, pp. 5 a 19 
no, el primero en fechar el lienzo en 1632, seguido ahora por la mayoría de los críticos e historiadores, siendo escasos y antiguos, Sterling, Cruzada, Beruete, Pantorba, Camón, los que sostuvieron la fecha de $1638^{2}$.

Palomino señaló también que el cuadro se hallaba en 1724 «en la clausura del convento de San Plácido», mientras Ponz lo localizó en 1776 más precisamente en la sacristía de la iglesia ${ }^{3}$, seguido por Ceán Bermúdez ${ }^{4}$. Sin embargo es de advertir que la sacristía del templo se edificó bastante después de realizarse la pintura, al tiempo de levantarse la nueva iglesia del monasterio entre 1655 y 1685 , por lo que ignoramos dónde estuvo primitivamente dentro de la clausura y qué función específica desempeñó ${ }^{5}$. De todas maneras esta ubicación en el convento de benedictinas de San Plácido dio pie a suponer que el Cristo Crucificado fue encargado por Felipe IV y regalado a las monjas como expiación de los supuestos amoríos con una joven religiosa, llamada sor Margarita, amoríos que impulsaban y amparaban el conde-duque de Olivares y su protegido don Jerónimo de Villanueva, fundador del monasterio.

La leyenda de los amoríos reales con la monja surgió de un libelo infamatorio, escrito y propalado a mediados del XVII contra don Gaspar de Guzmán, libelo titulado «Relación de todo lo sucedido en el casso del Convento de la Encarnación Benita» ${ }^{6}$. Dicha leyenda, por lo anecdótica y pintoresca, encontró particular aceptación entre los escritores románticos del siglo XIX, y así la recogió en apéndice -aunque suprimiendo los pasajes más escabrosos, don Ramón de Mesonero Romanos en $1861^{7}$. Inmediatamente fue difundida por otros cronistas madrileños como José Amador de los Ríos y Ángel Fernández de los Ríos ${ }^{8}$. Es de advertir, sin embargo, que ninguno de estos escritores mencionó la pintura de Velázquez ni la relacionó con los pecados del rey descritos en la leyenda. Esto lo insinuó por primera vez, en 1855, un historiador del arte, don Gregorio Cruzada Villaamil: «Se atribuye la pintura al 1638, mandada pintar por el Rey a Velázquez quizás en desagravio del ruidoso escándalo acaecido en el convento de la Encarnación Benita de San Plácido en el que figura el Protonotario de Aragón». Pero Cruzada no era tan cándido como otros autores que luego creyeron auténtica la leyenda, porque pensaban que ofrecía una explicación cabal de la motivación del cuadro velazqueño. A renglón seguido propuso efectivamente otra hipótesis, la de que el lienzo fue encomendado en 1638 por don Jerónimo de Villanueva para celebrar la absolución otorgada aquel año por la Inquisición, tanto a su persona como a las de las monjas, que habían sido acusadas y encarceladas tras un largo y ruidoso proceso ${ }^{9}$. Volveré enseguida a este punto.

Creo que es hora de abandonar de una vez para siempre el infundio que vincula el origen de la extraordinaria pintura de Velázquez con una leyenda que no tiene fundamento histórico

\footnotetext{
${ }^{2}$ M. Gómez Moreno, «El Cristo de San Plácido», Boletín de la Sociedad Española de Excursiones, XXIV, septiembre de 1916, pp. 177-188. Concuerdan con su opinión actualmente López Rey, J. Brown, J. Gállego, A.E. Pérez Sánchez, etc. Los últimos catálogos del museo del Prado señalan también el año de 1632 como el de la pintura del cuadro. También las recientes investigaciones sobre técnica de Velázquez apuntan claramente en esta dirección: cfr. Carmen Garrido Pérez, Vélazquez. Técnica y evolución, Museo del Prado, Madrid 1992, pp. 279-287.

${ }^{3}$ Viaje de España, tomo V, Madrid 1776, edición moderna de M. Aguilar, Madrid 1947, p. 473.

${ }^{4}$ Diccionario histórico..., tomo V, Madrid 1800, p. 179.

${ }^{5}$ Mercedes Agulló y Cobo, «El monasterio de San Plácido y su fundador, el madrileño don Jerónimo de Villanueva, Protonotario de Aragón», Villa de Madrid, XII, n 47, 1975, pp. 37-50. Sobre los avatares del cuadro hasta su entrada en el museo del Prado en 1829 véase Alfonso E. Pérez Sánchez, «El Cristo de Velázquez», en Velázquez, Fundación de Amigos del Museo del Prado-Galaxia Gutenberg, Barcelona 1999, pp. 335-349.

${ }^{6}$ Biblioteca Nacional, Mss. 18.659; véase al respecto el libro de Carlos Puyol Buil, Inquisición y política en el reinádo de Felipe IV. Los procesos de Jerónimo de Villanueva y de las monjas de San Plácido, C.S.I.C., Madrid 1993, pp.29 y ss.

${ }^{7}$ El antiguo Madrid, B.A.E., Obras completas de Mesonero Romanos, IV, Madrid 1967, pp. $221-222$.

${ }^{8}$ Historia de la villa y corte de Madrid, III, Madrid 1873, pp. 328-329; Guía de Madrid, 1876, p. 317.

${ }^{9}$ Gregorio Cruzada Villaamil, Anales de la vida y de las obras de Diego Velázquez de Silva, Madrid 1885, pp. $114-116$.
}

AEA, LXXVII, 2004, 305, pp. 5 a 19 

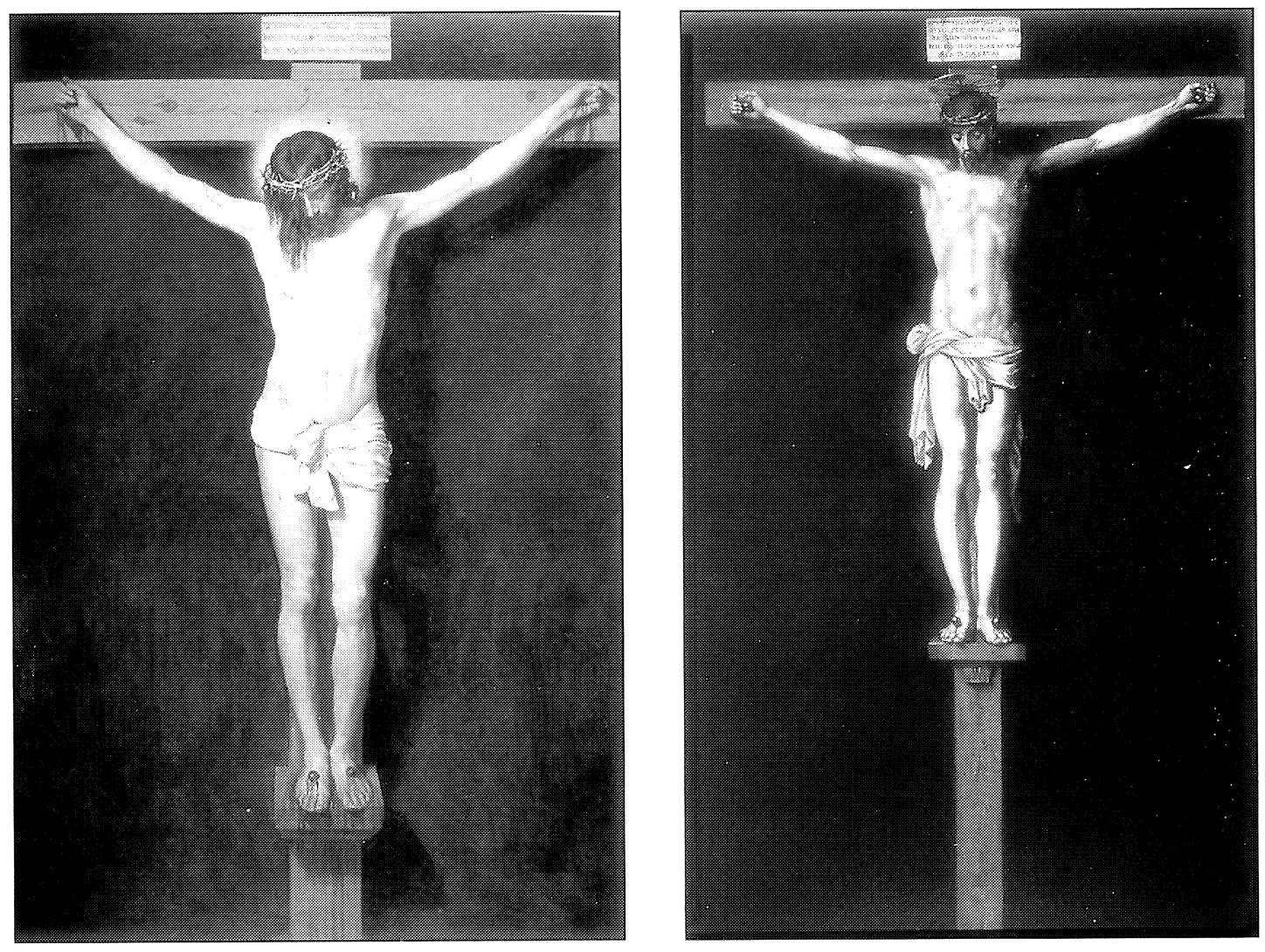

1

3

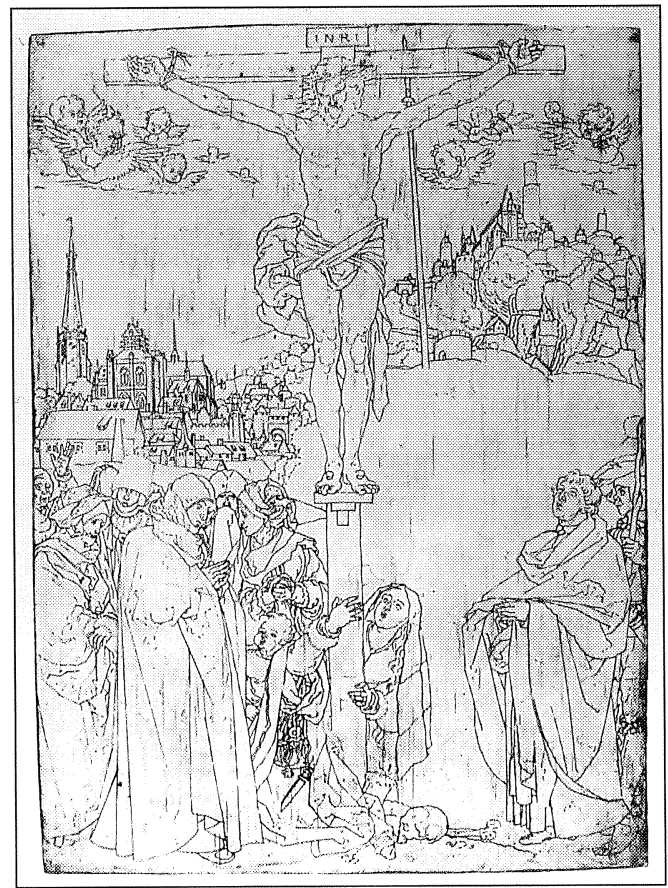

Fig. 1. D. Velázquez: Cristo Crucificado, Museo del Prado.

Fig. 2. P. Pacheco: Cristo Crucificado, Fundación Rodríguez Acosta, Granada.

Fig. 3. A. Durero: Calvario, British Museum, Londres. 
ninguno ${ }^{10}$. Ya en 1914 se encargó de refutar tal infundio Pedro Beroqui ${ }^{11}$, y lo hizo nuevamente con amplitud y varia erudición el doctor Gregorio Marañón, quien atribuyó el éxito del libelo antiolivarista a la vigencia del mito, entre folclórico y literario, del donjuanismo español. Pudo además comprobar en los archivos de San Plácido que existió una monja llamada sor Margarita de la Cruz, pero vivió muchos años después de los hechos fantaseados por la leyenda, entre 1653 y $1699^{12}$. Por otro lado las más recientes investigaciones sobre los procesos inquisitoriales del convento han remachado en el clavo. En ellos apenas se encuentran referencias a contactos de Felipe IV con las monjas del monasterio. Sí consta por una carta temprana de la priora, sor Teresa Valle de la Cerda, al conde duque de Olivares, la visita de los reyes al convento en 1627 con motivo de la fiesta de san Benito. Un año después la misma priora aconsejaba a Felipe IV, a través de Olivares, que moderase sus pasiones y cambiase de vida, amenazándole en caso contrario con grandes castigos, pero se refería a los galanteos que por entonces mantenía con la cómica María Calderón, conocida vulgarmente como La Calderona ${ }^{13}$. Pero desde que en mayo de 1628 se iniciaron los procesos del Santo Oficio contra las religiosas del monasterio acusadas de herejía y posesión diabólica, las escasas relaciones con los reyes se cortaron radicalmente. No deja de ser significativa a este propósito la anécdota que relata el jesuita Pedro Pimentel en carta de 14 de julio de 1632, año en que ahora se fecha por la mayoría el cuadro de Velázquez. Una de las azafatas de la reina Isabel de Borbón, hija de la marquesa de La Puebla, le pidió alguna cosa para regalar a un fraile, protegido de su madre, que marchaba a Perú, nombrado obispo de Chachapoyas: «Dijo la muchacha a la Reyna, deme V. Magd. alguna cossa para dar a mi obispo; ella dijo a doña Ana de Mendoza, mira en las navetas si ay algo, halló un relicario y la muchacha pússose luego a profetizar y decir diabluras; avisaron a la Reyna del accidente que le avía dado..., volvió en sí y a lo mismo; la Reyna muy turbada se lo contó al Rey que aquel relicario era de San Plácido; el Rey muy turbado, ¿no le dijo a V. Magd. que quemase todo lo que tuviese de San Plácido, con esto qué maravilla que esto passase?» ${ }^{14}$

Descartado en absoluto que Felipe IV encargase a Velázquez el Cristo Crucificado para obsequiarlo al convento de San Plácido, parece lógico que distintos autores se acordasen del fundador y patrono del monasterio, don Jerónimo de Villanueva, para asignarle ese cometido. Así lo hizo, como se dijo, Gregorio Cruzada Villaamil, seguido después por otros muchos historiadores. Esta hipótesis debe matizarse. En primer lugar, si bien hay constancia de algunos donativos de pinturas hechos por el Protonotario del convento, no se ha podido documentar de manera fehaciente que entre las pinturas se encontrase el cuadro velazqueño. Así en una carta de la priora Teresa Valle al confesor fray Francisco García Calderón, escrita durante la Semana Santa de 1628, se dice: «El lunes a las nueve de la mañana, cuando tañían a tercia, vino nuestro don Jerónimo contento como una pascua y le trujo a doña Ana para la portería cuatro cuadros que le acababan de costar por muy baratos trescientos ducados de la almoneda del Padre Confesor (de Felipe III) Aliaga: el uno de la Adoración de los Reyes con un marco hecho un ascua de oro, de tan linda y grave hechura que vale muchos ducados; el otro de Nues-

\footnotetext{
${ }^{10}$ Pese a ello el mito se sigue repitiendo todavía en publicaciones recientes, como la de María Águeda Castellano Huerta, El convento de San Plácido. Historia, arte y leyenda en el corazón de Madrid, La Librería, Madrid 2003, pp. 81-87. Pero aún es peor que se recoja nada menos que en la cartela explicativa del Cristo velazqueño en el museo del Prado.

"Adiciones y correcciones al catálogo del Museo del Prado, I, tipografía del Colegio de Santiago, Valladolid 1914, pp. 36-38.

12 «Los misterios de San Plácido», en Libro homenaje al profesor Martineche, París 1939, pp. 444-465; El Conde-Duque de Olivares, Espasa, 26 ed., Madrid 1998, pp. 266-272.

${ }^{13}$ Carlos Puyol Buil, op. cit., pp. 86-89. Algunas de las cartas al conde-duque de doña Teresa Valle de la Cerda han sido publicadas recientemente por Isabel Barbeito, Cárceles de mujeres en el siglo XVII. Proceso inquisitorial de San Plácido, Castalia, Madrid 1991, pp. 125-163.

${ }^{14}$ Real Academia de la Historia, Mss. 9-3687, fols. 230r-231v.
}

AEA, LXXVII, 2004, 305, pp. 5 a 19 
tra Señora con el Niño y San Juan, grandiosa pintura y de la misma manera el marco que la Adoración de los Reyes; otro es el Desposorio de Santa Catalina, lindísima cosa, que le diera a mi Padre mil gozos el verlas» ${ }^{15}$.

Por una carta de pago otorgada por Villanueva el 18 de septiembre de 1637 constó que había gastado 66.000 reales «que importaron los ornamentos, plata, láminas y pinturas que a entregado para el servicio del culto divino en el dicho Convento» ${ }^{16}$. En este lote pudo ir comprendido el cuadro velazqueño, si bien es verdad que la cantidad de reales en su totalidad parece un tanto exigua si en ella iba incluido el precio de la pintura de Velázquez, el cual hubo de ser elevado, toda vez que el de la plata y los ornamentos consumirían su mayor parte. Finalmente en 1640, en una bóveda bajo la escalera del convento, se depositaron veinte cajas, algunas muy grandes, con «escritorios, colgaduras, pinturas y fuentes de plata», que se trasladaron en carros desde el domicilio de Villanueva. Pero resulta inverosímil que entre las pinturas se contase el Crucificado de Velázquez, no sólo por lo avanzado de la fecha sino además por el lugar en que se pusieron ${ }^{17}$.

A primera vista semeja poco convincente que el Protonotario hubiese encargado el Cristo Crucificado para destinarlo al convento de la Encarnación benita cuyas religiosas habían sido delatadas a la Inquisición en mayo de 1628, acusadas de la herejía alumbradista, de posesión diabólica, de falsa profecía y de prácticas indecorosas. A finales de junio la abadesa, la priora y la mayor parte de las monjas habían sido trasladadas a las cárceles secretas de la Inquisición de Toledo, a quien competía dictaminar y sentenciar el caso por hallarse Madrid dentro de su jurisdicción. Los procesos individualizados se iniciaron en el mes siguiente y las sentencias contra doña Teresa Valle de la Cerda y otras religiosas se fueron dictando entre marzo y julio de 1630. Fueron condenadas a abjurar «de levi» de sus errores, a ser privadas de voz pasiva por diez años y activa por cuatro y a permanecer en conventos de Toledo, no pudiendo regresar al de San Plácido por espacio de cuatro años. Por consiguiente no hubiera tenido sentido que don Jerónimo de Villanueva encargara en 1632 una pintura tan costosa para donarla a un monasterio que, aun siendo fundación suya, se encontraba en aquel momento casi vacío.

El propio Protonotario comenzó asimismo a ser denunciado ante el Santo Oficio casi a la par que las monjas, a comienzos de junio de 1628. Uno de los puntos de que fue acusado y en el que se puso especial énfasis fue el que hubiese ordenado pintar a Julio César Semín - quien fue llamado a testificar el 18 de aquel mes- la imagen de su Ángel de la Guarda con el nombre, señas, inscripciones y manera que el demonio había señalado a una de las religiosas. El de don Jerónimo se llamaba Lauro y su figura de mancebo fue retocada, una vez que el pintor genovés la terminó, añadiéndole a los pies un dragón a tenor de lo que reveló, por boca de una de las monjas, el demonio llamado Serpiente. Villanueva llevó la pintura a su casa hasta que la Inquisición entró en conocimiento de ello y entonces la devolvió al convento ${ }^{18}$. El Protonotario debió quedar escaldado de pinturas que no se atuviesen a las convenciones de la más estricta ortodoxia. Dado el puesto que don Jerónimo ostentaba entonces

\footnotetext{
${ }^{15}$ Isabel Barbeito, op. cit., pp. 144-145.

${ }^{16}$ Mercedes Agulló, op. cit., p. 39.

${ }^{17}$ Otros papeles de Villanueva que podían ofrecer alguna pista sobre el asunto que nos ocupa fueron incautados después de la caída de Olivares en 1643 y de la reapertura del proceso inquisitorial en ese mismo año, pero el paradero final de tales documentos comprometedores sigue siendo un misterio. Sin embargo esos papeles eran de asuntos políticos, como se comprueba por el inventario que hizo de ellos el secretario del conde-duque Antonio Carnero, y no parece que se refiriesen a asuntos privados y personales; cfr. John H. Elliot, El Conde-Duque de Olivares, Crítica, Barcelona 1990, pp. 644-645.

${ }^{18}$ Esta acusación contra Villanueva fue renovada cuando se reabrió su proceso en 1643, aportándose entonces muchos más pormenores; véase G. Puyol Buil, op. cit., pp. 234, 361 y 194. La presencia de Ángeles de la Guarda en las visiones imaginarias de muchas religiosas del Siglo de Oro, asignándoles nombres y atributos exóticos como Rosauro, Uriel, Lauro, etc., se detecta, por ejemplo, en Juana de la Cruz, Luisa de la Ascensión y María de Ágreda; véase al respecto Ronald Cueto, Quimeras y sueños. Los profetas y la monarquía católica de Felipe IV, Universidad de Valladolid 1994, passim.
} 
pues, además de Protonotario de Aragón, era desde 1630 secretario del despacho, es decir quien atendía personalmente los asuntos con el rey, se intentó implicar a su protector Olivares para que su proceso inquisitorial no pasase adelante, absolviéndole mediante una penitencia que pudiese hacer en secreto. A semejante proposición contestó el conde-duque que «no podía aconsejar aquello al Protonotario, teniéndole por inocente, sin ver o entender primero que tuviese culpa que necesitase remedio». Fue entonces, en enero de 1632, cuando Villanueva entregó al Inquisidor General, el cardenal Antonio Zapata, un memorial de autodelación que consistía más en un alegato de defensa que en un reconocimiento de sus culpas. En consecuencia el Consejo General del Santo Oficio emitió el 30 de julio un decreto por el que suspendía el proceso contra el encausado, pues «en lo que toca a este sujeto no toca al Sancto Oficio el proceder en esta causa por no tener calidad de oficio». Jerónimo de Villanueva quedó entonces libre, sobre todo desde que el 22 de noviembre se le entregó copia oficial de aquel decreto ${ }^{19}$.

Pienso que fue en este preciso momento, a saber entre el 30 de julio y el 22 de noviembre de 1632, cuando el Protonotario encargó el cuadro de Cristo Crucificado de Velázquez. Pero no como acto de expiación de sus culpas o como penitencia impuesta por la Inquisición, como ha escrito algún estudioso ${ }^{20}$, pues ni fue reconocido culpable ni tal penitencia existió, según acabamos de ver. La pintura se mandó hacer seguramente como acción de gracias a Dios por la finalización del enojoso proceso y por haber salido indemne de él. Además, aunque las monjas de San Plácido se encontraban ausentes del convento y no podían regresar a Madrid por sentencia inquisitorial hasta 1634 , de hecho debió ser suavizada esta pena, puesto que hay constancia de que ya en febrero de 1633 la priora Teresa Valle de la Cerda y su hermana Isabel estaban en su monasterio madrileño ${ }^{21}$. Por otra parte las obras de su construcción, costeadas por don Jerónimo, no se habían interrumpido pese a los procesos inquisitoriales. Si no entonces, por lo menos poco después pudo aquél hacer entrega del lienzo velazqueño a su fundación. Ahora bien ¿por qué Villanueva eligió para la pintura el tema del Cristo Crucificado? Más lógico hubiera sido que encargase a Velázquez —a quien debía conocer bien por su amistad con el conde-duque, protector de ambos, y también porque llevaba cuenta de los gastos particulares de Felipe IV, entre los cuales hubo varios lienzos del pintor - una Anunciación, toda vez que el monasterio estaba dedicado a la Encarnación, misterio del que era particularmente devoto ${ }^{22}$.

Aquí es donde encajan otras motivaciones que hasta ahora no han sido tenidas en cuenta. La tremenda conmoción que produjo en la corte la noticia de que unos criptojudíos portugueses habían profanado sacrílegamente un Crucifijo, ultrajándolo, vejándolo, azotándolo y quemándolo, tubo que afectar particularmente a Villanueva y al conde-duque en virtud de las implicaciones políticas de que se quiso revestir el caso. El suceso había tenido lugar en 1630, mientras Velázquez se encontraba de viaje en Italia, y fue celosamente ocultado por la Inquisición durante el entablamiento del consiguiente proceso, prácticamente paralelo al de las monjas de san Plácido y del Protonotario, no revelándose al público hasta que fue dado a conocer repentinamente con motivo del Auto de Fe celebrado a comienzos de julio de 1632. Este proceso y su enorme impacto emocional en la sociedad de la época han sido estudiados reciente-

\footnotetext{
${ }^{19}$ G. Puyol Buil, op. cit., pp. 249-259.

${ }^{20}$ Jonathan Brown, Velázquez. Pintor y cortesano, Alianza, Madrid 1986, pp. 160-161.

${ }^{21}$ A.H.N: Inquisición, legajo 3.693, citado por Puyol Buil, p. 259.

${ }^{22}$ Bien conocidos son los pagos efectuados a Velázquez, a través de Villanueva, por los cuadros que pintó para el Salón de Reinos del Buen Retiro; véase María Luisa Caturla, «Cartas de pago de los doce cuadros de batallas para el Salón de Reinos», Archivo Español de Arte, XXXII, n 132, 1960, pp. 333-356; Corpus Velazqueño. Documentos y textos, Ministerio de Educación y Cultura, Madrid 2000, tomo I, pp. 102-109.
}

$A E A$, LXXVII, 2004, 305, pp. 5 a 19 

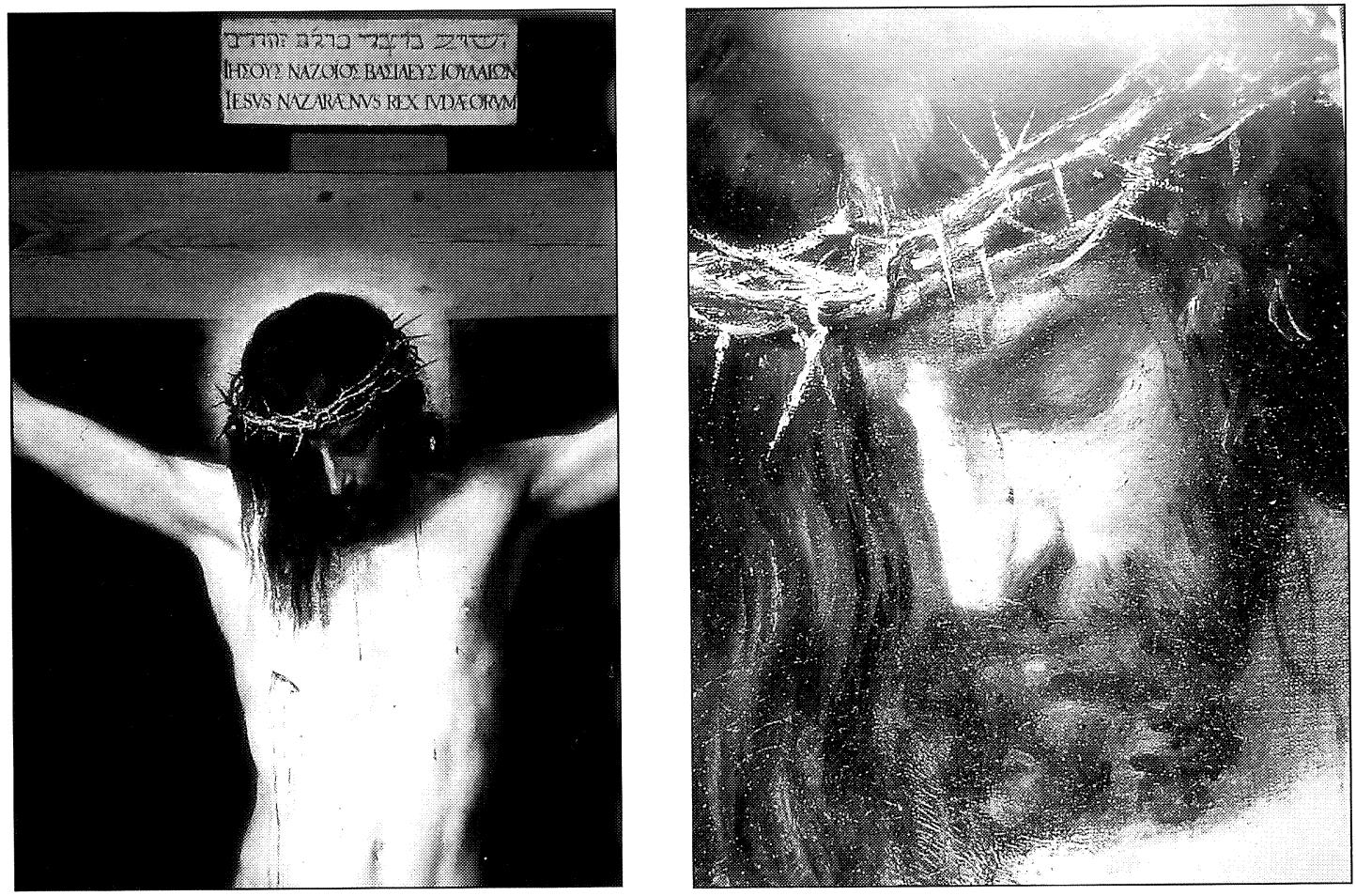

6
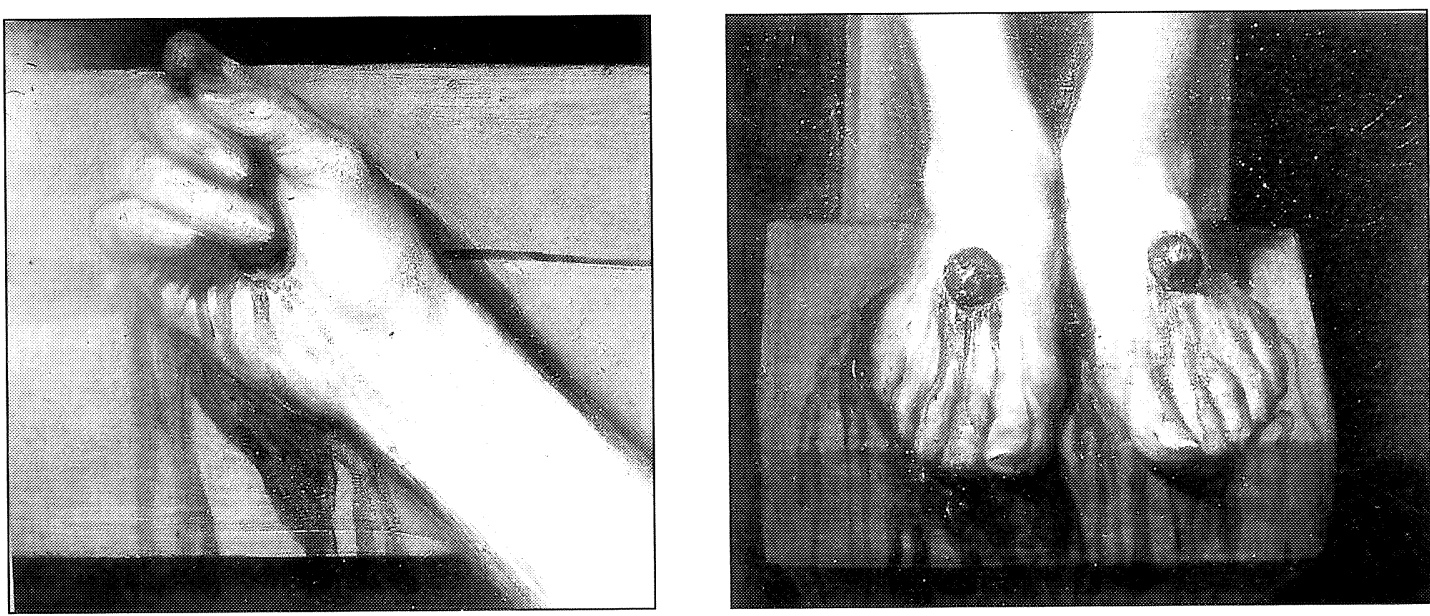

Fig. 4. D. Velázquez: Cristo Crucificado, detalle.

Fig. 5. D. Velázquez: cabeza del Cristo Crucificado.

Fig. 6. D. Velázquez: detalle de la mano izquierda del Cristo Crucificado.

Fig. 7. D. Velázquez: detalle de los pies del Cristo Crucificado.

AEA, LXXVII, 2004, 305, pp. 5 a 19 
mente con toda meticulosidad, después de haberse examinado las pruebas acusatorias originales conservadas en el Archivo Histórico Nacional ${ }^{23}$.

Los principales implicados fueron las parejas formadas por Miguel Rodríguez e Isabel Núñez Álvarez, de 60 y 40 años respectivamente, Hernán Báez y Leonor Rodríguez, de 60 y 53, y la viuda de 70 años Beatriz Núñez. Todos ellos eran originarios del norte de Portugal, concretamente de la Beira Alta, región de la que procedían muchos judíos, comerciantes de pequeños negocios de tejidos y lencería, que habían emigrado a la corte de Madrid en busca de una vida más próspera tras la recesión económica de su país de origen a comienzos del xvII y, también, huyendo de la tremenda intolerancia de la Inquisición portuguesa comparada con la relativa lenidad con que desde el reinado de Felipe III procedía el Santo Oficio español. Esta relativa lenidad se acrecentó en el período que nos ocupa, especialmente desde que en 1628 el condeduque de Olivares se estaba esforzando en proteger a banqueros portugueses de origen judío para que sustituyesen, como asentistas de la corona, a los tradicionales banqueros genoveses. Dicha protección — que no abarcaba ni mucho menos a todos los «marranos» portugueses establecidos en Madrid, sino a los de considerable peso económico- acarreó a Olivares fama de filojudío, uno de los varios motivos que manejaron sus enemigos políticos para destruirle y atraer hacia su persona y la de sus colaboradores la odiosidad de las masas populares ${ }^{24}$.

Los portugueses que fueron procesados en el Auto de Fe en 1632 se habían establecido en la corte el año de 1629, donde alquilaron habitaciones en una casa de la calle de las Infantas. Otra portuguesa, Juana de Silva, sincera conversa, sospechó de algunas prácticas, que coincidían con las que habitualmente realizaban los criptojudíos, y los delató a la Inquisición. En julio de 1630 fueron arrestados paulatinamente y conducidos a las cárceles del Santo Oficio de Toledo para ser interrogados. La cosa no hubiera probablemente pasado a mayores, pero se interpuso una acusación inesperada. El hijo menor del matrimonio formado por Miguel Rodríguez e Isabel Núñez Álvarez, un niño de seis años llamado Andresillo, vagaba por la ciudad tras la detención de sus padres, viniendo a parar al taller del maestro de seda Agustín Vergara y solicitando que le diera trabajo. Preguntado el niño sobre la causa del arresto de sus padres contestó que había sido «porque azotaban a un Cristo poniéndole una soga y allí (en la casa de la calle de las Infantas) lo azotaban con unos espinos y luego lo metían en el fuego y lo volvían a sacar y lo azotaban de nuevo y lo metían en un cofre y que a su casa acudían muchos portugueses y portuguesas». Vergara llevó a Andresillo a presencia del familiar del Santo Oficio Juan Dionisio de Portocarrero e, interrogado por él, confirmó lo dicho anteriormente «porque veía todo lo que hacían por un agujero de la puerta de la cocina». Los miembros del Consejo de la Suprema desconfiaron de aquella testificación por tratarse de un niño de corta edad, pero el 16 de septiembre hicieron una inspección de la casa de la calle de las Infantas acompañados por Andresillo, el cual «juró por la cruz y por su vida que vió mas de cincuenta veces,

\footnotetext{
${ }^{23}$ Juan Ignacio Pulido Serrano, Injurias a Cristo. Religión, política y antijudaismo en el siglo XVII, Universidad de Alcalá de Henares 2002. De este texto hago abundante uso, pues corrige y amplía los datos que publicó en 1709 el capuchino Mateo de Anguiano en el libro La nueva Jerusalén en la que la perfidia hebraica reiteró con nuevos ultrajes la pasión de Christo en la sacrosanta imagen del Crucifijo de la Paciencia en Madrid y augustos y perennes desagravios de nuestros cathólicos monarcas D. Phelipe IV el Grande y D. Isabel de Borbón, A. Sancha, Madrid 1709. Resumió lo más sustancioso de la prolija narración del capuchino Juan Antonio Álvarez de Baena en su Compendio histórico de las grandezas de la coronada villa de Madrid, Sancha, Madrid 1786, pp. 158-163, copiándole literalmente cuantos historiadores y cronistas de Madrid se ocuparon de este dramático asunto.

${ }^{24}$ Julio Caro Baroja, Los judíos en la España moderna y contemporánea, Istmo, Madrid 1986, II, pp. 66 y ss; Antonio Domínguez Ortiz, La clase social de los conversos en Castilla durante la Edad Moderna, Madrid 1955, ed. facsímil de la Universidad de Granada, 1991, pp. 110-123; James C. Boyajian, Portuguese Bankers at the Court of Spain, 1625-1650, Rutgers University Press, New Brunswick 1983; Bernardo J. López Belinchón, «Olivares contra los portugueses. Inquisición, conversos y guerra económica», en Historia de la Inquisición en España y América, B.A.C., Madrid 2000, III, pp. 499-530; Michael Alpert, Criptojudaismo e Inquisición en los siglos XVII y XVIII, Ariel, Madrid 2001, pp. 67-91; Juan Ignacio Pulido Serrano, Los conversos en España y Portugal, Arco Libros, Madrid 2003, pp. 55-69.
}

AEA, LXXVII, 2004, 305, pp. 5 a 19 
unas de día y otras de noche, juntarse en un aposento del cuarto principal a Miguel Rodríguez, su padre, y otros... que se reunían y cerraban la primera puerta de entrada al cuarto... y azotaban a un Cristo en la cocina de los dichos primeros aposentos». Con todo los ministros del Consejo Supremo continuaron considerando que esta declaración «no era de mucha sustancia». En un tercer interrogatorio el niño añadió un detalle que sorprendió terriblemente a los inquisidores, pues añadió que «cuando le azotaban decía el Cristo que por qué le azotaban y que respondían sus padres que, aunque le pesase y amargase, le habían de azotar» ${ }^{25}$.

Naturalmente los ministros del Santo Oficio de Toledo procuraron por todos los medios que los encausados, mayores de edad, ratificaran lo narrado por el menor, sin omitir la tortura. Todos acabaron confesando, aunque algunos - y entre ellos la madre de Andresillo- no admitieron que la imagen de Cristo hablase, pues «si ella viera tan gran milagro, saliera de su ceguedad y se convirtiera, reconociendo sus muchas culpas». También declararon, en vista de que el cuerpo del delito, el Crucifijo, no aparecía, que «estando a solas en la casa lo hicieron pedazos y la cruz en que estaba y que hecharon los pedazos en un brasero de barro lleno de brasas que allí estaba». El 19 de mayo de 1632 la Inquisición de Toledo hizo pública la sentencia, condenando a morir a Miguel Rodríguez, Isabel Álvarez, Hernán Báez, Leonor Rodríguez y Beatriz Núñez, mientras que otros encausados, por su menor edad y participación indirecta en los delitos, lo fueron a pena de reclusión perpetua.

La historiografía hebrea nunca creyó que los hechos que dieron lugar a la condena hubieran acaecido realmente, pues los judíos se mostraban respetuosos con las prácticas religiosas ajenas y eran enemigos de toda violencia física. De esta manera opinó ya a fines del siglo XVII el médico judío portugués Isaac Cardoso, para quien las pruebas aportadas por el Santo Oficio contra sus compatriotas fueron débiles e inciertas, ya que se derivaron de una confesión arrancada por la tortura ${ }^{26}$. Este estado de opinión ha arrastrado a algunos historiadores modernos a considerar que el proceso inquisitorial fue un amaño y que, ya antes de iniciarlo, la sentencia estaba dada, puesto que los infelices mercaderes portugueses fueron la víctima propiciatoria que era necesario sacrificar para aplacar la oleada de odio antisemítico que había levantado la política tolerante de Olivares ${ }^{27}$. Pienso, sin embargo, que el milagro del Crucifijo hablando a sus torturadores nunca se produjo y que su confesión de última hora, admitiéndolo, fue el último recurso que utilizaron algunos de los reos para librarse de la pena capital; pero que el ultraje, la vejación e incluso el azotamiento de la imagen fue un hecho real me parece algo incuestionable. Como escribe recientemente David M. Gitliz, «el crucifijo fue blanco predilecto del desprecio y hostilidad de los judíos falsamente conversos en cuanto objeto de la idolatría cristiana y como emblema del aspecto del cristianismo que más difícil se les hacía aceptar, la divinidad del Cristo. Las denuncias contra profanaciones del Crucifijo aparecen tantas veces en los documentos, en lugares tan dispersos y con testimonios tan diferentes, en muchos casos testigos oculares, que habría que creer que docenas de tribunales inquisitoriales independientes entre sí indujeron a declaraciones y confesiones falsas. Yo me inclino a creer que sí ocurría, porque es congruente con una pauta de irreverencia criptojudía hacia las manifestaciones materiales de la fe cristiana» ${ }^{28}$.

Pero aunque el hecho de los ultrajes sacrílegos hubiera sido un amaño tramado por la Inquisición, lo que no se puede negar es que, una vez hecho público, produjo en toda España,

\footnotetext{
${ }^{25}$ J.I.Pulido Serrano, Injurias a Cristo...,pp. 132-153.

${ }^{26}$ Yosef Hayin Yerushalmi, From Spanish Court to Italian Guehtto: Isaac Cardoso. A Study in Seventheent-Century Marranism and Jewish Apologetics, Columbia University Press, Nueva York 1971 (hay traducción española de la editorial Turner), pp. 105-122; de la misma opinion muestra ser Michael Alpert, op. cit., pp. 87-90.

${ }^{27}$ Esta es la tesis en líneas generales expuesta y defendida por el citado J. I. Pulido Serrano.

${ }^{28}$ Secreto y engaño. La religión de los criptojudíos, Junta de Castilla y León, Salamanca 2003, pp. 168-169. La edición original en inglés de este libro fue publicada en 1996 por The Jewish Publication Society.
} 
especialmente en Madrid, una conmoción incalculable. Por lo pronto el Auto de Fe en el que se había de castigar a los recalcitrantes judíos y que inicialmente se debía celebrar en Toledo, donde fueron juzgados, fue inopinadamente trasladado a la corte, decisión que causó un verdadero tumulto popular en la ciudad imperial. La toma de aquella decisión no se debió al cardenal Zapata, como se ha argumentado recientemente, sino a los propios reyes Felipe IV e Isabel de Borbón, quienes no consintieron perderse tan solemne y pública ocasión de manifestar su celo. Escribía Matías Novoa: «Hízose esta consulta al Rey y, deseando castigarlos, quiso hallarse en el Auto para dar ejemplo a sus vasallos y al mundo entero de su fe y religión; y viendo que el tiempo no daba para hacer jornada por corta que fuese a Toledo, por los insufribles calores del verano y por ser en medio de él, lo mandó hacer en la corte» ${ }^{29}$. La presencia de los soberanos, que aguantaron las once horas que duró el Auto, fue tanto más significativa cuanto que pocos años antes, en enero de 1624, no asistieron a otro impresionante Auto de Fe, celebrado igualmente en la capital, en que fue condenado a morir otro hebreo por la línea materna, Benito Ferrer Catalán, quien había arrebatado la hostia a un sacerdote mientras decía misa, haciéndola pedazos y pisoteando luego los fragmentos ${ }^{30}$.

El Auto de Fe que nos atañe tuvo lugar en plena canícula el 4 de julio de 1632 en la Plaza Mayor, «siendo la cosa más grandiosa que jamás se ha visto», según el jesuita P. Luis de la Fuente. Contra lo que era costumbre, el tablado se levantó no junto a la acera de la Panadería, sino en la de Mercaderes, es decir a poniente, por considerarse esta zona más apropiada para gozar de la sombra en aquel día caluroso del verano. Se encargó del diseño y construcción del tablado el maestro de las obras reales, Juan Gómez de Mora, ascendiendo los gastos a más de 5.000 ducados ${ }^{31}$. El propio arquitecto fue comisionado también para escribir y publicar el relato oficial del hecho, que describió con extensa y prolija minuciosidad, particularmente en lo relativo a los asistentes y al protocolo cortesano; añadió además la narración de los actos de desagravio oficiales a Cristo Crucificado que se verificaron a seguido del Auto de $\mathrm{Fe}^{32}$. Felipe IV, que contempló el desarrollo de la inacabable ceremonia desde un balcón de la casa del conde de Barajas, hizo el consabido juramento de defender la fe, perseguir a los herejes y amparar a la santa Inquisición, juramento que luego se tomó al pueblo asistente. Debió de ser en este momento cuando el conde-duque de Olivares, que asistía desde un sitio vecino al del rey, «se hechó sobre el valcón y poniendo la mano en el pecho dijo tres veces amen muy recio, y dirán que no es buen christiano, y el señor protonotario también y anduvo allí en el tablado muy ministro del tribunal...» ${ }^{33}$. Finalmente se leyó la sentencia a pena capital a los seis reos portugueses quienes, por haberse arrepentido y reconciliado, fueron estrangulados antes de proceder a la quema de sus cadáveres junto a la Puerta de Alcalá.

Repito que el impacto emotivo que produjo el saberse que aquellos desgraciados judíos habían profanado sacrílegamente una imagen del Crucificado y que, pese a haber chorreado

\footnotetext{
${ }^{29}$ Historia e Felipe IV, Rey de España, CODOIN, tomo LXIX, imprenta de M. Ginesta, Madrid 1875, p. 181. El jesuita Andrés Mendo daba otra razón complementaria, escribiendo el 19 de junio de 1632 al P. Rafael Pereira: «En Toledo avía de aver avido Auto de la Inquisición; dícese que ha de ser en Madrid porque la Reyna lo desea ver y, como está preñada, no puede salir de Madrid», Real Academia de la Historia, Ms. 9-3867, fol. 183v.

${ }^{30}$ Andrés de Almansa Mendoza, «Relación el Auto público de la Fe que se celebró en esta Corte, domingo 21 de enero de 1624» en José Simón Díaz, Relación de los actos públicos celebrados en Madrid (1541-1650), Instituto de Estudios Madrileños, Madrid 1982,pp. 286-290.

${ }^{31}$ Emilio Meneses García, «Construcción del tablado para el Auto de Fe de 1632», Revista de Archivos, Bibliotecas y Museos, LXXII, 1965-1966, pp. 168-174.

32 Relación del Auto de Fe que se celebró en Madrid, domingo quatro de Julio de MDCXXXII, folleto de 25 folios, Biblioteca Nacional V.E. 182-32 (reproducido en su mayor parte por J. Simón Díaz, op.cit., pp. 414-432). Se publicaron otras crónicas de este Auto de Fe, por ejemplo la que ordenó escribir la propia Inquisición a Gaspar Isidro de Argüello y todas ellas obtuvieron gran éxito de público, que las leyó ávidamente en toda la península; véase sobre el asunto J.I. Pulido Serrano, op. cit., pp. 217-218.

${ }^{33}$ Real Academia de la Historia, Mss. citado, fols. 230r-231v.
}

AEA, LXXVII, 2004, 305, pp. 5 a 19 

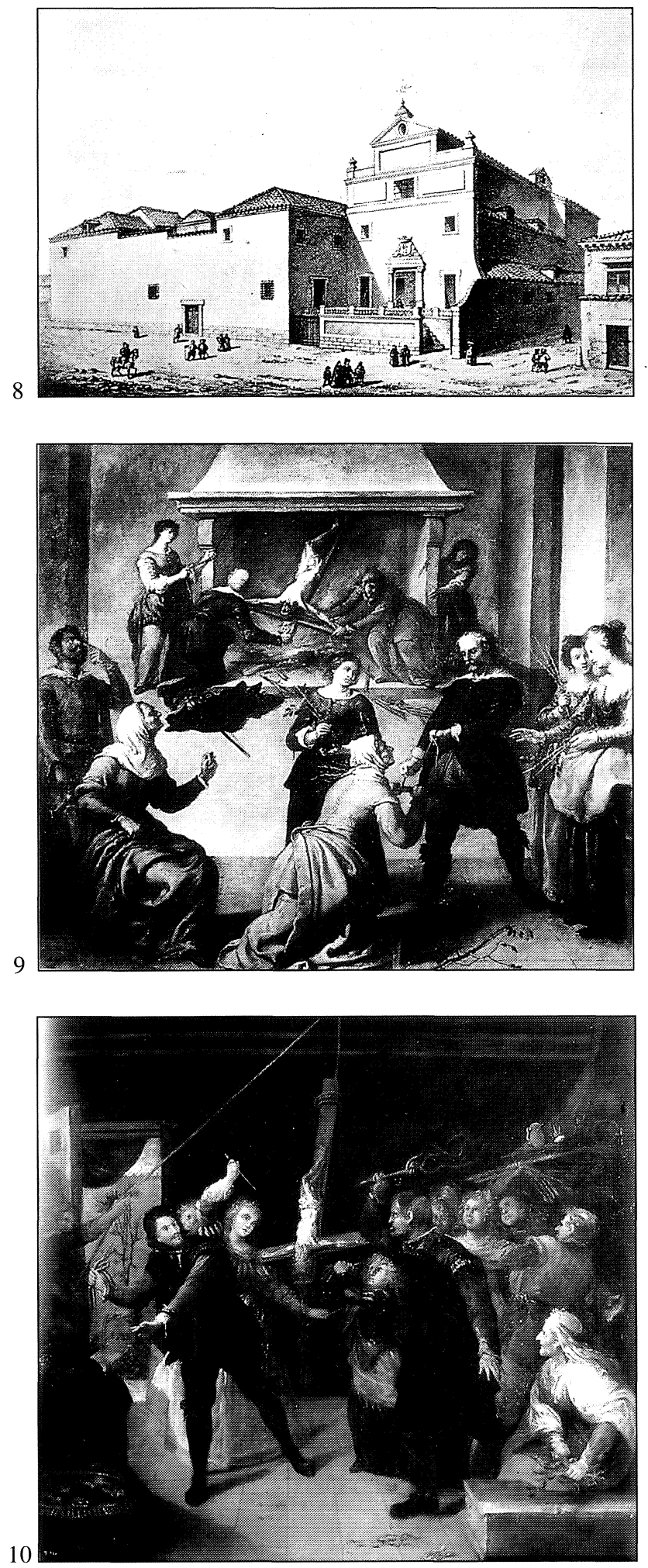

Fig. 8. Convento de Capuchinos del Cristo de la Paciencia, Madrid. Grabado de Letre.

Fig. 9. F. Camilo: Injurias a un Crucifijo, Museo del Prado.

Fig. 10. F. Rizi: Flagelación de un Crucifijo, Museo del Prado. 
sangre y haberles hablado, permanecieron inconmovibles en su saña, fue enorme no sólo en los reyes y sus ministros sino en toda clase de público. Por eso no pareció suficiente el castigo infligido a los culpables, sino que inmediatamente se organizaron actos de desagravio para reparar los ultrajes a Cristo Crucificado. Tomó la delantera la tía del monarca, sor Margarita de la Cruz, quien no contenta con haber hecho celebrar un octavario en la iglesia de las Descalzas Reales, dejó en sus testamento una gruesa manda para que anualmente se hiciese una fiesta de desagravio ${ }^{34}$. Al último día del octavario asistió Felipe IV vestido de riguroso luto, tomando parte en la procesión que, con un Crucifijo, recorrió la plazuela del monasterio. También lo hizo a la ceremonia de desagravio que organizó el otro monasterio de patronato real, el de la Encarnación, en este caso acompañado por la reina; en la correspondiente procesión, por delante del atrio de la iglesia, se llevó igualmente un Crucifijo bajo palio, escoltado por los archeros y las guardias españolas y alemana. De todas maneras la ceremonia de reparación de mayor envergadura fue la que tuvo lugar en el regio Alcázar el 14 de septiembre, fiesta de la Exaltación de la Santa Cruz. En la capilla, ricamente entoldada de terciopelo carmesí, se expuso la Flor de Lis, es decir el riquísimo relicario que contenía un clavo de la cruz de Cristo. Asistió el monarca a la misa que celebró el Nuncio. Por la tarde se organizó una procesión por los corredores altos del patio del rey, en cuyos ángulos se levantaron cuatro altares, el primero costeado por sor Margarita de la Cruz, el segundo por el infante Baltasar Carlos, el tercero por la reyna y el último por el rey. Los altares estaban presididos por imágenes bien de Cristo Crucificado, bien de la flagelación de Cristo. La procesión, en la que también el Nuncio portaba un Crucifijo de bulto, fue dando la vuelta a los altares, donde se hizo estación para interpretar cantos y elevar plegarias ${ }^{35}$.

Siguiendo la iniciativa de la casa real, las parroquias de San Sebastián, San Luis, la Orden Tercera de San Francisco y otras muchas comunidades e instituciones religiosas arbitraron ceremonias de desagravio, envolviendo a la corte durante el verano y el otoño de 1632 en una densa atmósfera de luto, dolor y sentimiento. Todavía, pasado un año, la cofradía de san Pedro Mártir, que englobaba a los familiares y ministros del Santo Oficio, organizó en la primavera de 1633 un acto de reparación y desagravio en el convento de Santo Domingo el Real, al que concurrió Felipe IV, predicando en la ocasión el célebre fray Félix Hortensio Paravicino ${ }^{36}$. Los cofrades de san Pedro Mártir institucionalizaron la memoria de los ultrajes a Cristo Crucificado, instituyendo una fiesta anual que los recordase y los reparase. A su ejemplo surgieron otras cofradías con el mismo propósito: la de San Millán con el título de esclavos del Cristo de las Injurias; la de los esclavos del Cristo de la Fe en la parroquia de san Sebastián; y la congregación del Cristo de los Desagravios en la de San Luis. También se convocaron, a usanza de la época, certámenes poéticos para que los ingenios de la corte execraran en sus versos las horribles injurias infligidas al Crucifijo por los judíos portugueses en 1630. Alcanzó enorme celebridad una de estas piezas que compuso Lope de Vega, titulada Sentimientos a los agravios de Cristo Nuestro Señor por la nación hebrea, que el vate dedicó al recién jurado Príncipe de Asturias, el infante Baltasar Carlos; constaba de 101 sextillas y fue incluida por su autor en la segunda parte de la Vega del Parnaso ${ }^{37}$.

\footnotetext{
${ }^{34}$ Fray Juan de la Palma, Vida de la Serenísima Infanta Sor Margarita de la Cruz, Madrid 1636, fols. 176-177.

${ }^{35}$ Además de la relación de todas estas fiestas de desagravio hecha por Gómez de Mora, también dio cuenta de ellas Antonio de León Pinelo, Anales de Madrid (desde el año 447 hasta el de 1658), edición de Pedro Fernández Martín, Instituto de Estudios Madrileños, Madrid 1971, pp. 292-293. 292.

${ }^{36}$ Fray Feliz Hortensio de Paravicino, Sermones cortesanos, edición de Francis Cerdán, Castalia, Madrid 1994, pp. 253-

${ }^{37}$ Obras no dramáticas de Lope de Vega y Carpio, edición de M. Menéndez y Pelayo, B.A.E., reedición de Atlas, Madrid 1950, pp. 359-361.
}

AEA, LXXVII, 2004, 305, pp. 5 a 19 
Tras esta larga digresión histórica volvamos al Protonotario don Jerónimo de Villanueva. Como ya se adelantó, probablemente a finales del verano o en el otoño de 1632 encargó a Velázquez la pintura de Cristo Crucificado para agradecer a Dios la interrupción de su proceso inquisitorial, ordenado por el Consejo Supremo. Era hombre sinceramente devoto, aunque tontamente crédulo y supersticioso, y por ello debió quedar especialmente conmocionado por la tremenda profanación del Crucifijo llevada a cabo por los judíos portugueses. Vimos cómo durante el Auto de Fe de 4 de julio hizo, al igual que el conde-duque, vehemente confesión de su fe y execración del acto cometido por los hebreos lusitanos, tanto más cuanto que a él y a su protector se les inculpaba de filosemitismo y de ser de alguna manera responsables de aquel acto de barbarie. Por consiguiente nada más lógico que escoger como asunto del cuadro velazqueño el de Cristo Crucificado, ofrecido luego a su fundación de san Plácido para que las religiosas pudiesen delante de él ofrecerle devotos sentimientos de veneración y desagravio. Existe además otro indicio manifestativo del interés que se tomó Villanueva por aparecer personalmente muy implicado en los actos de reparación al Crucifijo sacrílegamente profanado. La casa de la calle de las Infantas, donde se había perpetrado aquél, fue demolida, el solar sembrado de sal y cercado por una valla. Poco después, por deseo de la reina Isabel de Borbón, se planeó edificar en aquel solar vacío un templo expiatorio servido por una comunidad de Capuchinos, y para ello se nombró una comisión de la que formó parte don Jerónimo de Villanueva. «Entre las personas que más desearon tomar a cargo esta obra —escribía fray Juan de Monzón - fue una el Protonotario de Aragón». Pienso que su intención no fue torpedear y poner toda clase de trabas al edificio, como se ha dicho, sino todo lo contrario, la de tomar a su cargo la financiación económica de la obra. Y si puso finalmente alguna traba fue por despecho "viendo que no le daban lugar para hacerse dueño de ella», pues esto hubiera representado el hacer sombra a la propia reina ${ }^{38}$.

También el mismo Diego Velázquez quedaría sumamente impresionado por un suceso que había convulsionado a la corte y a Madrid entero, por lo que recibiría con doblado interés el encargo que le hizo Villanueva de pintar un Cristo Crucificado de tamaño natural. Ya Carl Justi intuyó hace años el genuino motivo de haber realizado el cuadro: «En aquella década de los treinta había aumentado mucho en Madrid la devoción a la cruz; había corrido el rumor de que unos judíos habían azotado a un Cristo y éste se había quejado clara y distintamente. La casa del crimen fue arrasada y eran innumerables las procesiones de expiación con hachones» ${ }^{39}$. El pintor sevillano puso especialísimo empeño en pintar un cuadro emotivo, profunda y religiosamente sentido. Incluso dio al lienzo un tratamiento más cuidadoso que en los de tema profano, como se percibe en la esmerada preparación del fondo, la molienda más menuda de los pigmentos y el modelado más empastado y preciso de la figura de Cristo ${ }^{40}$. Se sirvió del prototipo de su maestro, Francisco Pacheco, de Cristo Crucificado con cuatro clavos sobre un fondo oscuro, aislado y sin acompañamiento de otras figuras ni de paisaje, porque este esquema se amoldaba perfectamente a sus propósitos. Una escena descriptivo-narrativa del Calvario, fijada en un tiempo y en un espacio histórico concreto, hubiera distraído la atención de lo fundamental del asunto. Velázquez se concentró en la figura de Cristo Crucificado, concibiéndola como un icono intemporal que convidase al uso íntimo y personal y a la efusión devota. Pero el artista intentó conjugar este aspecto devocional con el sesgo conmemorativo que había de tener una imagen que conmemorase un suceso histórico singular, tal como debió ser la intención del comitente don Jerónimo de Villanueva. Si para el

${ }^{38}$ J.I. Pulido Serrano, op. cit., p. 283.

${ }^{39}$ Carl Justi, Velázquez y su siglo, Espasa, Madrid 1953, p. 405.

${ }^{40}$ Jonathan Brown y Carmen Garrido, Velázquez: la técnica del genio, Encuentro, Madrid 1998, pp. 69-72. 
primero de los aspectos se valió de los rasgos del prototipo de Pacheco, para expresar el segundo utilizó la dimensión monumental de 250 por 170 centímetros, que no son las reducidas que habitualmente tiene los cuadros de devoción, pero que se avenían perfectamente al cariz conmemorativo de un exvoto ${ }^{41}$.

Por otro lado Velázquez, aun sin renunciar a la expresión de una impasible serenidad y de una belleza clásica que había aprendido en su reciente viaje a Italia, acentuó el aspecto agudamente doloroso que correspondía al hecho histórico del maltrato por los judíos de un Crucifijo del que había manado abundante sangre. Los borbotones de sangre que brotan de los agujeros de las manos se deslizan por los extremos del travesaño horizontal hasta empaparlos; los dedos de los pies están inundados de sangre que, como un torrente, anega el supedáneo y chorrea por la cepa vertical de la cruz; la cabeza, los ojos, la boca y la barba de Cristo están surcados por hilillos de sangre que, procedente de la corona de espinas, descienden hasta su pecho; en fin de la herida abierta del costado salen también hilos de sangre que, bajando por las costillas, llegan a atravesar el perizoma o paño de pureza y acaban en el muslo de la pierna izquierda. «En el examen con fluorescencia ultravioleta se observa la existencia en todo el cuerpo del Crucificado de mayor cantidad de sangre de la que ahora tiene. Un gran número de gotas se han decolorado, tal vez por una limpieza antigua con productos alcalinos, pero otras fueron veladas ligeramente en superficie por el propio artista» ${ }^{42}$. Francisco Pacheco había aconsejado no abusar de la sangre en las imágenes de Cristo Crucificado; si su yerno y discípulo lo hizo en este caso, fue seguramente para conmemorar el suplicio a que sometieron los judaizantes portugueses al Crucifijo de que brotó abundante sangre. Sin embargo en el cuerpo del Cristo velazqueño no se perciben verdugones ni huellas de la flagelación.

Además, aunque el pintor empleó un fondo oscuro para aislar la figura del crucificado, lo restregó con unos toques verdosos irregulares que lo convierten en una superficie vibrante, como han descubierto la limpieza y restauración de 1990. Sobre este fondo han salido a la superficie las sombras arrojadas por la luz, desde el extremo superior izquierdo, del brazo izquierdo, del cuerpo y del supedáneo, sobre el lado derecho del cuadro. De este modo la figura de Cristo adquiere un relieve tridimensional asombroso que la asimila a una escultura, acaso para refrescarnos la memoria de que su referente fue un Crucifijo de bulto profanado por los judíos. No fue este recurso el único de que se sirvió el pintor para resaltar la plasticidad de la imagen. La cabeza de Cristo, ligeramente inclinada al morir, se desprende del fondo gracias al halo luminoso que la circunda. El hombro izquierdo está más flexionado y adelantado que el derecho; por el contrario el pie y la pierna derechas han retrocedido ligeramente, mientras el pie y la rodilla izquierdas se hallan más avanzadas. Estos sutiles y casi imperceptibles movimientos se reflejan igualmente en el torso y en el pecho, despojando a la entera figura de la rigidez y sequedad del modelo de Pacheco. Parece como si Velázquez hubiera puesto todo el empeño para que su Cristo Crucificado se desviara de la descripción que hizo Francisco de Rioja del Cristo de cuatro clavos pachequiano: «Vese plantada la figura sobre el supedáneo como si estuviera en pie... sin torcimiento feo ni descompuesto, así como convenía a la soberana grandeza de Cristo» ${ }^{43}$

También se apartó el pintor sevillano de la transcripción del título la cruz que puso su suegro en su pintura, tomándola de la que le proporcionaron el mencionado Rioja y el jesuita Luis

\footnotetext{
${ }^{41}$ El modelo de Cristo Crucificado con cuatro calvos fue tomado por Pacheco de Alberto Durero, como él mismo lo confesó, porque era para él autoridad iconográfica inapelable. Además del lienzo de Cristo Crucificado, de la colección de M. Gómez Moreno (fundación Rodríguez Acosta de Granada), Pacheco realizó también un dibujo de un Crucificado de cuatro clavos rodeado de figuras, probablemente preparatorio para una pintura de retablo; véase Benito Navarrete Prieto, «Durero y los cuatro clavos», Boletín del Museo del Prado, XVI, 1995, pp. 7-10.

${ }^{42}$ Carmen Garrido Pérez, Velázquez. Técnica y evolución, p. 287.

${ }^{43}$ F. Pacheco, El Arte de la Pintura, edición de Bonaventura Bassegoda, Cátedra, Madrid 1990, p. 719.
}

AEA, LXXVII, 2004, 305, pp. 5 a 19 
del Alcázar. La escribió, frente al corriente acrónimo INRI, como síntoma de erudición en hebreo, griego y latín, suprimiendo en todos estos idiomas el encabezamiento HIC EST y poniendo simplemente IESUS NAZARENUS REX IUDEORUM. Pero cometió errores de ortografía al escribir en griego NAZOIOS en lugar de NAZORAIOS, y en latín NAZAERENUS en vez de NAZARENUS. Quien había trascrito más correctamente el título trilingüe había sido naturalmente el Greco ${ }^{44}$.

Cuando finalmente se edificó entre 1643 y 1661 la iglesia expiatoria llamada del Cristo de la Paciencia ${ }^{45}$, los cuadros que se pintaron y se colgaron de las paredes de la capilla, situada exactamente sobre el sitio de la profanación, fueron todos narrativos, representando los distintos momentos de las injurias, azotes y quema del Crucifijo por los judaizantes lusitanos. Se encargaron a Francisco Rizi dos (incluido el del Despojo de las vestiduras a Cristo que se hizo para el retablo mayor de la iglesia) y uno respectivamente a Francisco Camilo, Francisco Hernández y Andrés de Vargas ${ }^{46}$. De ellos apenas queda memoria y excepto el de Vargas, perdido en un incendio, y el del Expolio, ahora expuesto en la catedral de la Almudena, los demás se hallan en los almacenes del museo del Prado. No así el de Velázquez, para nada narrativo sino intensamente devoto, de una hondura y emotividad religiosas que todavía siguen vigentes.

${ }^{44}$ Véase a este respecto J. Brown, Images and Ideas in Seventheenth-Century Spanish Painting, Princeton University Press, New Jersey 1978, pp. 59-62; sobre el mismo asunto, referido a las esculturas sevillanas de Cristo Crucificado, cfr. Alberto Villar Mobellán, «La fortuna crítica de Juan de Mesa: razones de un infortunio», en Juan de Mesa (1627-2003): visiones y revisiones, Universidad de Córdoba, Córdoba 2003, pp. 113-117.

${ }^{45}$ José Luis Barrio Moya, «Cristóbal de Aguilera y el desaparecido convento de los Capuchinos de la Paciencia de Cristo», Anales del Instituto de Estudios Madrileños, XVIII, 1981, pp. 187-191. La iglesia y el convento fueron demolidos en 1837 para dar lugar a la entonces llamada plaza de Bilbao, ahora Vázquez de Mella; Juan Antonio Gaya Nuño, La arquitectura española en sus monumentos desaparecidos, Espasa, Madrid 1961, p. 390.

${ }^{46}$ Diego Angulo Iñiguez, «Francisco Rizi, su vida, cuadros religiosos anteriores a 1670», A.E.A., XXX, n 122, 1958, p. 100; Id., «Francisco Camilo», A.E.A., XXXI, n 125, 1959, pp. 96-97; Alfonso E. Pérez Sánchez, Carreño, Rizi, Herrera, Catálogo de la Exposición, Museo del Prado, Madrid 1986, pp. 246-47 y 292-93; Diego Angulo y Alfonso E. Pérez Sánchez, Pintura madrileña. Segundo tercio del siglo xvII, C.S.I.C., Madrid 1983, pp. 367-368; Alfonso E. Pérez Sánchez, Francisco Camilo: un pintor en el Madrid de Felipe IV, Real Academia de la Historia, Madrid 1998, pp. 44-45.

$A E A$, LXXVII, 2004, 305, pp. 5 a 19 